\title{
Diversification through Catastrophe Bonds: Lessons from the Subprime Financial Crisis
}

\author{
Peter Carayannopoulos and M. Fabricio Perez \\ Financial Services Research Centre, School of Business and Economics, Wilfrid Laurier University, \\ 75 University Av. West, Waterloo, ON, N2L 3C5, Canada. \\ E-mails: pcarayanno@wlu.ca; mperez@wlu.ca
}

Are catastrophe bonds (CAT bonds) zero-beta investments? Are they a valuable new source of diversification for investors? We study these questions by analysing the dynamic relations of CAT bond returns and the returns of the stock, corporate bond and government bond markets. Our multivariate GARCH model results provide evidence that CAT bonds are zero-beta assets only in non-crisis periods. We document that CAT bonds were not immune to the effects of the recent financial crisis. With the collapse of Lehman Brothers, CAT bond returns became significantly correlated with the market. However, the relatively small effect of the crisis on CAT bonds compared with other asset classes make them a valuable source of diversification for investors. Finally, it seems that the improved structures for new CAT bonds issued since 2009 have been positively received by the market, as CAT bond betas returned to pre-crisis levels.

The Geneva Papers (2015) 40, 1-28. doi:10.1057/gpp.2014.14

Keywords: catastrophe bonds; financial crisis; GARCH; diversification

Article submitted 12 July 2013; accepted 21 March 2014; published online 20 August 2014

\section{Introduction}

Catastrophe bonds (CAT bonds) are often said to be "zero-beta" investments. ${ }^{1}$ Their structure attempts to isolate investors from market-related risks and expose them only to event risk. As a result these securities are considered to be a valuable new source of diversification for investors. We examine this argument in the context of the 2008-2009 subprime financial crisis.

Research on CAT bonds has focused mainly on their pricing. ${ }^{2}$ In contrast, relatively little research has focused on the relation of CAT bonds with the rest of the market and the claim that they are zero-beta instruments. In this paper we investigate the correlation of CAT bond

\footnotetext{
${ }^{1}$ Litzenberger et al. (1996).

${ }^{2}$ Three different approaches are used for pricing models. The first one involves an actuarial approach along the lines of traditional reinsurance contracts (as an example see Lane and Mahul, 2008). The second approach uses a utility maximisation framework to develop the pricing mechanisms (see recent examples in the work of Egami and Young, 2008 and Dieckmann, 2009). More widespread is a third alternative that uses a contingent claims approach in order to develop the pricing models (recent examples are the works by Lee and Yu, 2007; Muermann, 2008; Chang et al., 2010; Hardle and Cabrera, 2010; Wu and Chung, 2010). For a detailed review, see Braun (2011).
} 
returns with other asset classes using a sample that includes pre- and post-crisis periods and a formal methodology that allows for time-varying correlations. In addition, we evaluate the effectiveness of CAT bonds as diversification instruments by estimating and analysing their dynamic hedge ratios ${ }^{3}$ and comparing them with hedge ratios of other asset classes.

Our main findings are threefold. First, our results imply that CAT bonds were not zerobeta assets during the financial crisis. The dynamic correlation coefficients of CAT bonds with the market and the corresponding hedge ratios are statistically significant during the crisis. We argue that weaknesses associated with both the structure of CAT bond trust accounts and the composition of the assets used as collateral in the trust account are the main drivers of these results. Assets used as collateral in these trust accounts proved to be of lesser than expected quality and, furthermore, counterparties in swap agreements, put in place in an effort to immunise collateral asset returns from market fluctuations, were exposed to considerable credit risk or even defaulted during the crisis.

Second, we find evidence that the effects of the financial crisis on CAT bonds disappear by the beginning of 2011, as the correlations with the market returned to their statistically insignificant pre-crisis levels. These results may imply that the new and improved collateral structures created for CAT bonds issued after 2009 have been perceived as effective by market participants. These new structures attempt to enhance the credit quality of the collateral asset and include limits to the type of assets permitted in the collateral account, and constant monitoring and reporting of the collateral account balance.

Finally, and more importantly, we find that the relative change of CAT bond hedge ratios during the financial crisis is extremely small compared with hedge ratio changes of other financial assets. Thus we conclude that CAT bonds are a superior diversification instrument. Our results provide further evidence of the extreme effects of the subprime crisis in the CAT bond market and of the persistency level of these effects.

To the best of our knowledge, there are only two previous empirical studies directly related to our research question. ${ }^{4,5}$ Cummins and Weiss ${ }^{4}$ present a preliminary analysis of the effects of the financial crisis on CAT bond returns. They compute (time-invariant) correlation matrices of CAT bond returns with several other investment indices and yield rates. Their results suggest that during normal economic conditions CAT bonds are close to zero-beta with respect to stock and bond returns. However, CAT bond returns during the crisis are significantly correlated with these markets.

Our study differs from Cummins and Weiss ${ }^{4}$ in three ways. First, we remove their assumption of time-invariant (constant) correlations coefficients by allowing for time-variant covariance matrices and correlation coefficients. We model the time series behaviour of asset's variances and covariances using a multivariate generalised autoregressive conditional heteroskedasticity (GARCH) model. The main advantage of our methodology is that it is designed to capture the stylised characteristic of time series and those of financial asset returns in particular, which exhibit volatility clustering. Large innovations, of either sign, tend to occur in bunches so that volatility may be viewed as positively serially correlated. One plausible explanation for

\footnotetext{
${ }^{3}$ Dynamic hedge ratios are estimated by the ratio of the covariance with the market and the variance of the market.

${ }^{4}$ Cummins and Weiss (2009).

${ }^{5}$ Gürtler et al. (2012).
} 
this phenomenon, which seems to be an almost universal feature of asset return series in finance, is that the information arrivals that drive changes in prices themselves occur in bunches rather than being evenly spaced through time. In contrast to simple constant correlation or moving correlation models, the multivariate GARCH model incorporates a level of persistency in correlations. Many applications in asset pricing, risk measurement and option pricing require an examination of the extent to which asset returns move together over time. For example, as a by-product of the models, we can easily estimate dynamic hedge ratios or time-varying betas. This type of model is particularly desirable around important financial events, such as the financial crisis, since we can clearly identify how persistent the effects of the event on the correlations between assets are. In addition, in order to formally test if the changes in the financial crisis are statistically significant, we apply Hamilton's ${ }^{6}$ two-state Markov regime-switching model. Using this methodology, we are able to identify clearly low and high correlation regimes, the average value of correlations during these regimes and test for statistical significance. Furthermore, we are able to better define starting and ending dates for the regimes.

Second, we analyse the effectiveness of CAT bonds as diversification instruments by estimating and analysing dynamic hedge ratios. If CAT bonds have relative low investment betas, then they can be used to diversify market risk. This question can be evaluated in the context of the subprime financial crisis, comparing the performance of CAT bonds with other investments such as corporate bonds and government bonds before, during and after the crisis. Using the variance covariance estimates from a multivariate GARCH model, we compute dynamic hedge ratios as in Kroner and Sultan ${ }^{7}$ for CAT bonds and other financial assets. Since the dynamic hedge ratios are estimated by the ratio of the covariance with the market and the variance of the market, they can be interpreted as time-varying betas.

Finally, given our extended sample ending in October 2013, we are able to analyse a postcrisis period. The extended sample also allows us to provide an assessment of the steps taken by participants in the CAT bond market in the aftermath of the financial crisis in order to reduce the exposure of these instruments to systematic market failures.

Most recently, in a study that explores the impact of disasters on CAT bond premiums, Gürtler et $a .^{5}$ also document a significant impact of the financial crisis on such premiums. Using a panel threshold regression model to determine which events induced a change of regime in CAT bond pricing, they find that the Lehman Brothers event and the Katrina event induced such changes. Our results support the Gürtler et al. ${ }^{5}$ main findings regarding the impact of major natural catastrophes on the CAT bond market. In addition, given the dynamic approach of our empirical methodology we are able to answer questions with respect to the persistency of these effects and, more importantly, in relation to other asset classes and markets. We find that major catastrophes increase dynamic correlations of CAT bonds and the market. However, our findings also suggest that the impact of natural catastrophes on correlations has been, at least to this day, much smaller than the impact documented during the financial crisis. Even the impact of Hurricane Katrina, the catastrophe with the largest insurance losses in our sample period, failed to reach levels, both in magnitude or persistency, observed during the financial crisis.

\footnotetext{
${ }^{6}$ Hamilton (1989).

${ }^{7}$ Kroner and Sultan (1993).
} 
The remainder of this paper is organised as follows. The next section describes the structure of CAT bonds. In the subsequent section, the data and research methodology are described. We evaluate empirically if CAT bonds are zero-beta assets in the latter section. We analyse the effects of the subprime financial crisis on CAT bonds, the structural failures that explain our empirical results, and the market solutions to these structural failures in the fifth section. In the penultimate section we study empirically the diversification benefits of the CAT bond asset class in the context of the financial crisis. Conclusions are presented in the final section.

\section{The structure of catastrophe bonds}

Global catastrophe insured losses have grown significantly over time. Although global losses of less than US\$10 billion per year were experienced during the 1970s and early 1980s, losses of more than US\$30 billion per year have often been experienced since the early 1990 s. $^{8}$ This increasing trend has continued since the year 2000, even after adjusting for inflation, as is shown in Figure 1. Global economic losses of less than US\$80 billion per year were experienced during years 2000 and 2001. Since 2003, however, losses have consistently surpassed the US\$100 billion mark, with the exception of years 2006, 2007 and 2009. Global economic catastrophe losses over US\$200 billion were observed in 2005, 2008, 2010, 2011 and 2012. As depicted in Figure 1, global catastrophe insured losses have experienced a similar pattern.

Given the dramatic increase in global economic and insured catastrophe losses, insurance markets have looked for innovative solutions to the problem of risk financing. In this context, CAT bonds have emerged as the predominant alternative risk financing tool. Since its development in the early 1990s, the market for CAT bonds has grown steadily over the years and has provided a significant source of risk capital to insurers and reinsurers. It constitutes a mechanism that allows insurance and reinsurance companies to transfer natural disaster risk and meet the funding demands of mega-catastrophes. As Figure 2 indicates, the CAT bond market grew from US\$633 million in 1997 to almost US\$7 billion in 2007. The subprime financial crisis of 2008-2009 did hamper this growth with US\$2.7 billion in 2008, US $\$ 3.4$ billion in 2009 and US $\$ 4.6$ billion in 2010. Risk capital outstanding has grown from a little over US\$4 billion at the end of 2004 to US\$12 billion at the end of 2009. It has remained fairly constant ever since with US\$11.9 billion outstanding at the end of $2011 .{ }^{8}$

The typical structure of a CAT bond is presented in Figure 3. The insurance or reinsurance company, usually referred to as the sponsor, that wants to transfer the risk of a natural catastrophe is not issuing the bond directly to the capital markets. Instead, it gets into a reinsurance agreement with a special purpose vehicle (SPV) that is usually located offshore. Subsequently, the SPV issues the bond to the capital markets. Proceeds of the bond are placed in a collateral trust account and used to purchase high-quality assets, such as shortterm treasuries or AAA-rated corporate securities, in accordance with conditions stipulated in the offering documents. The vast majority of CAT bonds use a total return swap (TRS) to convert the fixed returns on the collateral securities to floating returns based on a widely

\footnotetext{
${ }^{8}$ See figure 8 in Guy Carpenter (2012).
} 


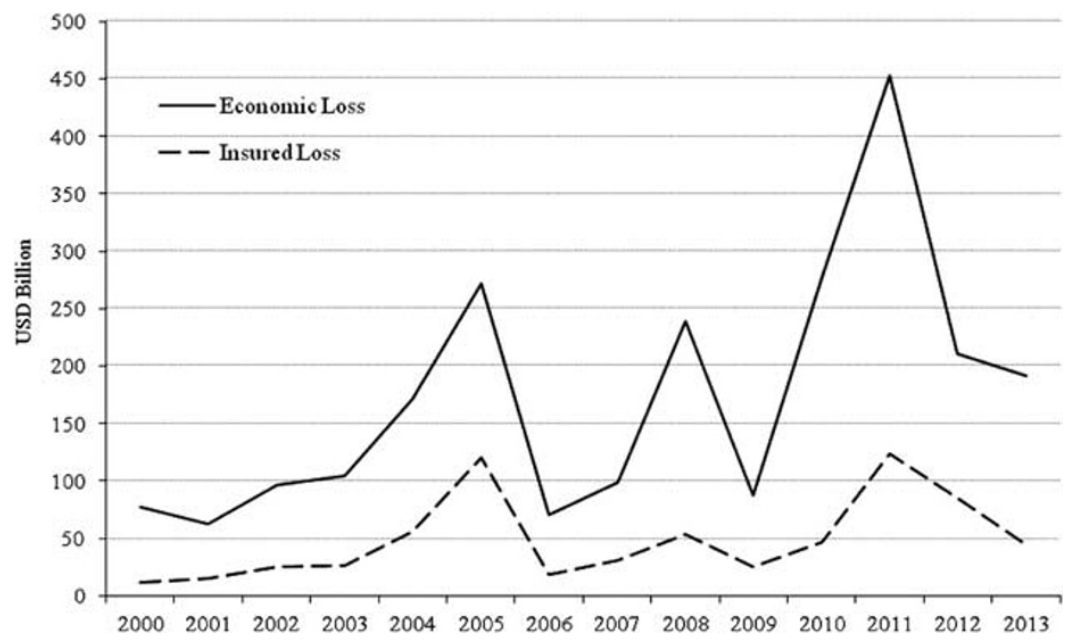

Figure 1. Global catastrophe economic and insured losses.

The figure depicts global economic catastrophe losses and global insured catastrophe losses in 2013 US\$ billion from 2000 to 2013. The graph was compiled with data from Aon Benfield, www.catastropheinsight.aonbenfield. com/Pages/Home.aspx.

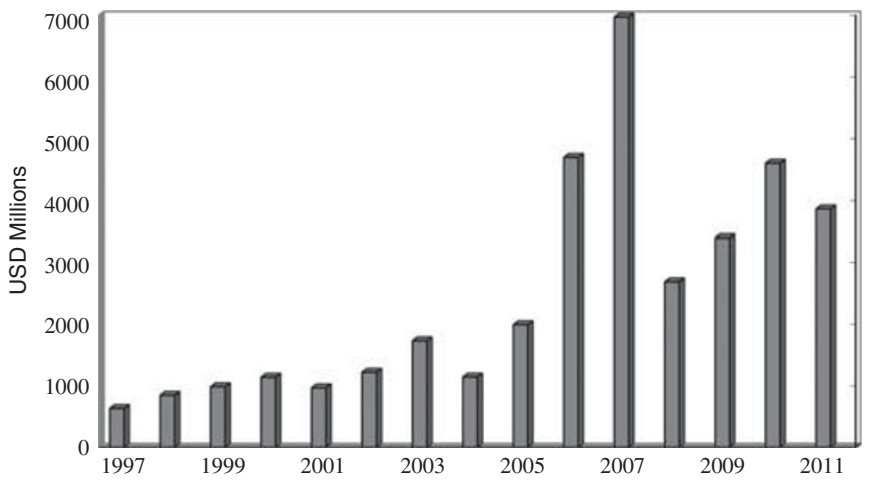

Figure 2. Catastrophe bond issuance 1997-2011.

The bars in the figure represent the total amount of CAT bonds issued by year for the period from 1997 to 2011 (in US\$ million).

Source: Guy Carpenter (2012).

accepted index, most commonly the London Interbank Offered Rate (LIBOR). The bond's interest and principal payments are contingent upon the insured catastrophic event occurring. On the occurrence of the event, proceeds are released from the SPV to help the insurer pay claims arising from the event. In the majority of the cases, investors' principal is fully at risk. Depending on the insurer's losses due to the occurrence of the insured event, investors could potentially lose the entire principal in the SPV. In return, investors receive a floating rate on their investment, most commonly LIBOR plus a risk premium. If the event does not occur during the life of the bond, they also receive the invested principal at maturity. 


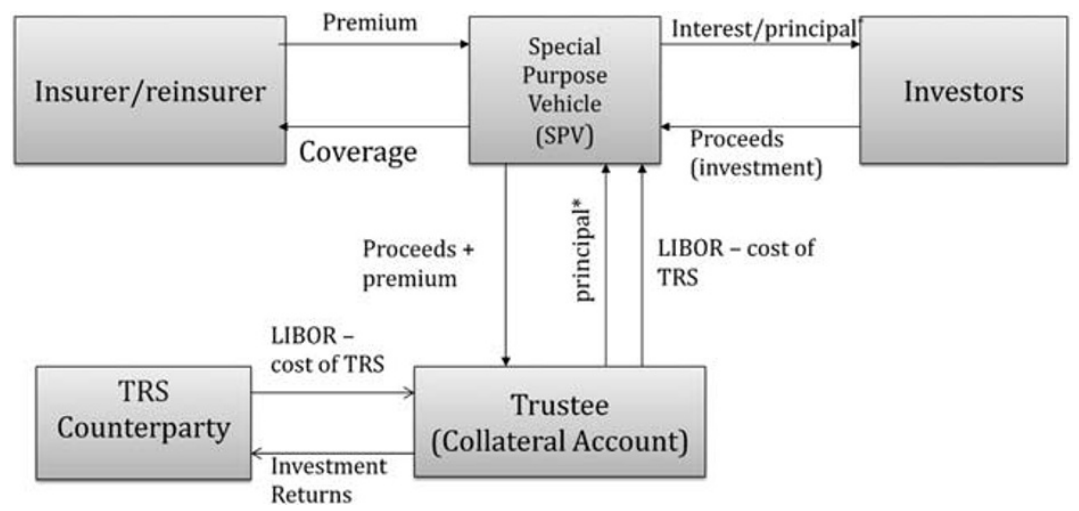

Figure 3. CAT bond flow of funds.

The figure depicts the structure of a typical CAT bond. The special purpose vehicle (SPV) serves as the intermediary between the insurer/reinsurer and investors and facilitates the process of the bond issuance. It oversees the creation and management of a trust account through which all the flows are directed. Often enough the presence of a total return swap (TRS) counterparty provides additional guarantees with respect to the value of the collateral and investment returns to investors.

*Investors' interest and/or principal receipts are contingent upon the occurrence of a CAT event. Interest is based on LIBOR plus a premium.

The role of the TRS is to immunise investors from collateral asset value fluctuations (mark-to-market) and eliminate the likelihood of default risk. Thus, this structure allows investors to gain exposure solely to the risk of the underlying peril. Since the TRS counterparty assumes the risk of movements in interest rates and the mark-to-market risk to the value of the collateral assets, the SPV and ultimately the investors are insulated from any investment-related risk. As a result, the CAT bond asset class should provide great diversification benefits to investors. On each interest payment date, the TRS counterparty guarantees investors a stream of LIBOR-based investment returns irrespective of the actual investment return earned on the collateral assets.

\section{Data and methodology}

Our CAT bond data is the BB CAT bond price index compiled by Swiss Re. Since 2007, Swiss Re has maintained four total insurance-linked securities return indices: an overall insurancelinked securities index (ILS index), a BB-rated index, a California earthquake index and a U.S. windstorm index. The starting year for the data is 2002. We follow Cummins and Weiss ${ }^{4}$ and focus on the broadest available indices, the ILS index and the BB-rated index. Since the ILS and BB indices are highly correlated, we report results using only the BB price index. ${ }^{9}$

\footnotetext{
${ }^{9}$ Our results are robust to the use of the overall index and are also robust to the use of the BB CAT bond total returns index compiled by Swiss Re. We used the BB CAT bond price index in order to be consistent with our market index, the SP\&500 which is also a price based index. We show in Appendix A (Figure A1) that the dynamic behaviour of CAT bonds returns is very similar no matter what index is used.
} 
Table 1 Descriptive statistics

\begin{tabular}{|c|c|c|c|c|}
\hline & $\begin{array}{l}\text { CAT bond } \\
\text { returns }\end{array}$ & $\begin{array}{l}\text { Corp. bond } \\
\text { returns }\end{array}$ & $\begin{array}{l}\text { Gov. bond } \\
\text { returns }\end{array}$ & $\begin{array}{c}S \& P 500 \\
\text { returns }\end{array}$ \\
\hline \multicolumn{5}{|l|}{ Descriptive statistics } \\
\hline Mean & -0.0054 & 0.0076 & 0.0005 & 0.0924 \\
\hline Median & -0.0027 & 0.0486 & -0.0280 & 0.1652 \\
\hline Maximum & 3.8927 & 3.1364 & 3.4020 & 11.4695 \\
\hline Minimum & -3.3212 & -5.8825 & -2.6475 & -16.8383 \\
\hline Std. dev. & 0.3726 & 0.7046 & 0.8373 & 2.5044 \\
\hline Observations & 614 & 575 & 614 & 614 \\
\hline \multicolumn{5}{|l|}{ Time series properties } \\
\hline First autocorrelation & 0.0920 & 0.1190 & -0.1210 & -0.0190 \\
\hline$P$-value of test for stationary & 0.0000 & 0.0000 & 0.0000 & 0.0000 \\
\hline \multicolumn{5}{|l|}{ Crisis effect } \\
\hline Mean before the crisis $(01 / 2002-11 / 2007)$ & -0.0078 & -0.0037 & 0.0017 & 0.0938 \\
\hline Std. dev before the crisis & 0.3700 & 0.5591 & 0.8221 & 1.9102 \\
\hline Mean during the crisis $(12 / 2007-05 / 2009)$ & -0.1140 & -0.0293 & 0.0661 & -0.4609 \\
\hline Std. dev during the crisis & 0.4052 & 1.2818 & 1.0940 & 4.4862 \\
\hline Mean after the crisis $(06 / 2009-10 / 2013)$ & 0.0349 & 0.0369 & -0.0271 & 0.3102 \\
\hline Std. dev after the crisis & 0.3566 & 0.5659 & 0.7545 & 2.2384 \\
\hline \multicolumn{5}{|l|}{ Katrina effect } \\
\hline Mean before Katrina (01/2002-07/2005) & 0.0086 & 0.0175 & 0.0077 & 0.0495 \\
\hline Std. dev before the crisis & 0.4054 & 0.6900 & 0.9736 & 2.098 \\
\hline Mean during Katrina (08/2005-12/2005) & -0.2609 & -0.0854 & -0.1331 & 0.0587 \\
\hline Std. dev during the crisis & 0.5488 & 0.3950 & 0.5471 & 1.2530 \\
\hline Mean after Katrina (01/2005-10/2013) & 0.0024 & 0.0100 & 0.0035 & 0.1096 \\
\hline Std. dev after the crisis & 0.3385 & 0.7224 & 0.7809 & 2.7169 \\
\hline
\end{tabular}

Note: We report descriptive statistics of our return data in percentage points. CAT bonds are the return of the BB CAT bond price index from Swiss Re. Corporate bonds are the FINRA-Bloomberg Active Investment Grade U.S. Corporate Bonds Index from Bloomberg. The government bond is the Barclays 5-7-year government bond index from Compustat. Data is weekly from 4 January 2002 to 11 October 2013, with the exception of the corporate bonds that start on 4 August 2002. We also report first-order autocorrelation coefficients and the $p$-value for the Augmented Dickey-Fuller test for unit roots.

Our proxy for the corporate bond market performance is the FINRA-Bloomberg Active Investment Grade U.S. Corporate Bonds Index; for the government bond market the Barclays 5 to 7-year government bond index is used and for the stock market the S\&P500 index. We have 614 weekly observations for all series, from 4 January 2002 to 11 October 2013, with the exception of the corporate bond series that starts on 4 August 2002 (575 observations). Descriptive weekly return statistics (mean, median, maximum, minimum and standard deviation) for our data series are presented in Table 1. 
Average weekly CAT bond return for the sample period is -0.0054 per cent. This negative average return can be explained by the impact of Hurricane Katrina. As we can see from the detailed descriptive statistics in Table 1, the average weekly return before and after Katrina is positive, and comparable with the average government bond returns. The standard deviation of CAT bonds returns is considerably lower compared with the other asset classes, which can be viewed as preliminary evidence of the advantage of CAT bonds as low risk investments.

The effects of the financial crisis on the average returns of the different asset classes can also be analysed from our statistics in Table 1. As expected, with the exception of government bonds, all other classes exhibited a significant reduction in their returns and an increase in volatility. It is also interesting to note that the change in volatility was much smaller for CAT bonds compared with the other asset classes. After the crisis, all asset classes with the exception of government bonds returned to positive return territory, but once again, the return-risk relationship seemed to favour CAT bonds as an interesting investment opportunity.

As mentioned earlier, Cummins and Weiss ${ }^{4}$ provide an analysis of the correlations of several markets with the CAT bond markets. We replicate their results with our weekly data in Table 2. Specifically, we calculate the correlation coefficients between CAT bond, corporate bond, government bond and the S\&P500 returns indexes. As in Cummins and Weiss, ${ }^{4}$ we present results for a pre-crisis sample (January 2002 to November 2007) and a crisis sample (December 2007 to May 2009). ${ }^{10}$ In addition, we present results for a postcrisis period with data from June 2009 to October 2013. Given the weekly nature of our data, our correlation coefficients are different in magnitude when compared with the ones calculated by Cummins and Weiss, ${ }^{4}$ but qualitatively similar, something that allows us to arrive to the same preliminary conclusions. Specifically for the pre-crisis period, we find that CAT bond returns are not significantly correlated with the corporate bond index and the S\&P500 index. We find a very small correlation of 0.128 with the government index that is significant at the 10 per cent but not at the 5 per cent and 1 per cent levels, as compared to Cummins and Weiss ${ }^{4}$ who find insignificant results in general. This can be explained by the small sample analysed together with the weekly nature of our data and a slightly different definition of the crisis period. However, Cummins and Weiss ${ }^{4}$ also find a small significant correlation between CAT bonds and 10-year government bonds.

For the crisis period, our results are qualitatively identical to Cummins and Weiss, ${ }^{4}$ and very similar quantitatively. We find a significant correlation of the CAT bond returns with the S\&P500 and the corporate bond index returns, equal to 0.252 and 0.475 respectively, compared with 0.305 and 0.465 in Cummins and Weiss. ${ }^{4}$ The correlation with the government bond index returns is not significant and small (0.054).

Finally in the post-crisis periods, the correlation coefficients become statistically not different from zero. For the S\&P500 returns case, the value drops to 0.058 , and for the corporate bond returns to 0.092 . From these preliminary results we conclude that the crisis

${ }^{10}$ Cummins and Weiss (2009) define the crisis period from July 2007 to January 2009. We use the crisis period as defined by the National Bureau of Economic Research; however, our conclusions are the same using both definitions of the crisis periods. 
Table 2 Correlation matrix of CAT bonds and other asset classes

\begin{tabular}{|c|c|c|c|c|}
\hline & $\begin{array}{l}\text { CAT bond } \\
\text { returns }\end{array}$ & $\begin{array}{l}\text { Corporate } \\
\text { bond returns }\end{array}$ & $\begin{array}{l}\text { Government } \\
\text { bond returns }\end{array}$ & $\begin{array}{l}\text { S\&P500 } \\
\text { returns }\end{array}$ \\
\hline \multicolumn{5}{|c|}{ Panel A: January 2002 to November 2007} \\
\hline CAT bond returns & 1 & & & \\
\hline Corporate bond returns & 0.003 & 1 & & \\
\hline $\begin{array}{l}\text { Government bond } \\
\text { returns }\end{array}$ & $0.128 *$ & $0.334 * * *$ & 1 & \\
\hline S\&P500 returns & 0.016 & $-0.104^{*}$ & $-0.269 * * *$ & 1 \\
\hline \multicolumn{5}{|c|}{ Panel B: December 2007 to May 2009} \\
\hline CAT bond returns & 1 & & & \\
\hline Corporate bond returns & $0.475 * * *$ & 1 & & \\
\hline $\begin{array}{l}\text { Government bond } \\
\text { returns }\end{array}$ & 0.054 & $0.235 * *$ & 1 & \\
\hline S\&P500 returns & $0.252 * *$ & $0.419 * * *$ & $-0.249 * *$ & 1 \\
\hline \multicolumn{5}{|c|}{ Panel C: June 2009 to October 2013} \\
\hline CAT bond returns & 1 & & & \\
\hline Corporate bond returns & 0.092 & 1 & & \\
\hline $\begin{array}{l}\text { Government bond } \\
\text { returns }\end{array}$ & 0.009 & $0.250 * * *$ & 1 & \\
\hline S\&P500 returns & 0.058 & $0.213 * * *$ & $-0.434 * * *$ & 1 \\
\hline
\end{tabular}

We report correlation coefficients for our data series described in Table 1 . The $*, * *, * * *$ represent significance at the 10,5 and 1 per cent significance levels, respectively.

had an effect on the risk-return relation of CAT bonds with other assets. This effect seems to be non-permanent, since in our post-crisis sample, the correlations return to previous precrisis levels.

The descriptive analysis just presented constitutes the main motivation for our study. Even though the results in Table 2 seem conclusive, they are based on an arbitrary choice of the pre-crisis, crisis and post-crisis periods. Moreover, the estimated correlations are calculated under the assumption that they are constant over the estimation period. This assumption seems restrictive under the stylised characteristic of financial time series that exhibit volatility clustering. Large innovations, of either sign, tend to occur in bunches so that volatility may be viewed as positively serially correlated. This stylised characteristic is especially important around significant financial events, similar to the recent financial crisis which also motivates our study.

Our empirically methodology focuses on the estimation of the time-varying relation between CAT bonds and other financial assets (i.e. dynamic correlations). As noted earlier, we are interested in studying if CAT bonds are zero-beta investments and, furthermore, if they are good diversification vehicles. The market beta is a function of the correlation between CAT bonds and the market factor, thus, analysing the dynamics of this correlation, we can tackle our first research question. Similarly, by analysing hedge ratios for CAT bonds and comparing them with hedge ratios of other financial assets we can make inferences with respect to the diversification potential through CAT bonds. Hedge ratios are also a function of the correlation between financial assets and the market factor. 
Specifically, we require an estimation of the conditional correlation between two random variables, $r_{1}$ and $r_{2}$, defined as follows: ${ }^{11}$

$$
\rho_{12, t}=\frac{E_{t-1}\left(r_{1, t} r_{2, t}\right)}{\sqrt{E_{t-1}\left(r_{1, t}^{2}\right) E_{t-1}\left(r_{2, t}^{2}\right)}} .
$$

In definition (1), the conditional correlation is a function of information known during the previous period. The conditional correlation lies in the interval $[-1,1]$, for all linear combinations and past realisations of the variables. Several estimators have been proposed for the conditional correlation. The simplest one is the rolling correlation estimator, defined as follows:

$$
\hat{\rho}_{12, t}=\frac{\sum_{s=t-n-1}^{t-1} r_{1, s} r_{2, s}}{\sqrt{\left(\sum_{s=t-n-1}^{t-1} r_{1, s}^{2}\right)\left(\sum_{s=t-n-1}^{t-1} r_{2, s}^{2}\right)}} .
$$

A shortcoming of this estimator is that it gives equal weight to all observations less than $n$ (an arbitrary number) and zero weight to older observations.

An alternative approach to estimate the dynamic correlations is multivariate GARCH (MGARCH) models. These models are based on the estimation of the conditional covariance matrix defined for the case of two variables as follows:

$$
E_{t-1}\left(r_{t} r_{t}^{\prime}\right)=H_{t}=\left[\begin{array}{ll}
h_{11, t} & h_{12, t} \\
h_{12, t} & h_{22, t}
\end{array}\right],
$$

where $r_{t}^{\prime}=\left(r_{1, t}, r_{2, t}\right)$ is the vector of random variables, $h_{i i, t}=E_{t-1}\left(r_{i, t}^{2}\right)$ are the conditional variances and $h_{12, t}=E_{t-1}\left(r_{1, t} r_{2, t}\right)$ is the conditional covariance.

Many specifications of the MGARCH model have been considered in the literature. The most general expression proposed by Engle and Kroner ${ }^{12}$ is the VEC model. For the case of $\operatorname{GARCH}(1,1)$ the covariance matrix is parameterised as follows:

$$
\operatorname{vec}\left(H_{t}\right)=\operatorname{vec}(\Omega)+A \operatorname{vec}\left(r_{t-1} r_{t-1}^{\prime}\right)+B \operatorname{vec}\left(H_{t-1}\right),
$$

where vec is the operator that converts a matrix into a column vector, and $\Omega, A$ and $B$ are matrices of parameters. Here the covariance matrix is modelled as a function of previous period variances and covariances. For the bivariate case the model is defined as follows:

$$
\left(\begin{array}{l}
h_{11, t} \\
h_{12, t} \\
h_{22, t}
\end{array}\right)=\left(\begin{array}{l}
\omega_{1} \\
\omega_{2} \\
\omega_{3}
\end{array}\right)+\left(\begin{array}{lll}
\alpha_{11} & \alpha_{12} & \alpha_{13} \\
\alpha_{21} & \alpha_{22} & \alpha_{23} \\
\alpha_{31} & \alpha_{32} & \alpha_{33}
\end{array}\right)\left(\begin{array}{l}
r_{1, t-1}^{2} \\
r_{1, t-1} r_{2, t-1} \\
r_{2, t-1}^{2}
\end{array}\right)+\left(\begin{array}{lll}
\beta_{11} & \beta_{12} & \beta_{13} \\
\beta_{21} & \beta_{22} & \beta_{23} \\
\beta_{31} & \beta_{32} & \beta_{33}
\end{array}\right)\left(\begin{array}{l}
h_{11, t-1} \\
h_{12, t-1} \\
h_{22, t-1}
\end{array}\right),
$$

where, $h_{i j, t}, \omega_{i}, \alpha_{i i}$ and $\beta_{i i}$ are elements of the matrices $H_{t}, \Omega, A$ and $B$, respectively.

One of the problems of the general VEC specification is that it requires the estimation of a large number of parameters, something that affects its reliability. Furthermore, the number of parameters increases exponentially with the number of variables analysed. In order to

\footnotetext{
${ }^{11}$ We assume without loss of generality that each variable has mean zero for this definition.

12 Engle and Kroner (1995).
} 
improve the reliability several restrictions to the VEC specification have been proposed in the literature.

The objective is to choose an MGARCH model that provides estimates of the variance matrix that are flexible enough to be realistic, but that are also parsimonious. However, there is a trade-off between model flexibility and parsimony. More flexible models involve the estimation of many parameters, and more parsimonious models require restrictions on the dynamics of the variance matrix. We use one of the most general specifications of the restricted VEC model, the diagonal VEC specification, which restricts matrices $A$ and $B$ to being diagonal. Our choice of model is based in two important aspects. First, we are interested in a very parsimonious model that requires estimation of few parameters. This is important because our sample size is relatively small (11 years of weekly data) and, more importantly, since the crisis period that we are interested in lasted less than two years. Second, since the financial crisis affected each financial asset in a different way, we are interested in a model that allows for different persistence levels in the variances and covariances of these assets. The diagonal VEC model is a very parsimonious model that also provides realistic estimates of the variance-covariance matrix.

Under the diagonal VEC model the variances and covariance between variables $r_{1}$ and $r_{2}$ are parameterised by the following equations:

$$
\begin{aligned}
& h_{11, t}=\omega_{1}+\alpha_{11}\left(r_{1, t-1}^{2}\right)+\beta_{11} h_{11, t-1}, \\
& h_{12, t}=\omega_{2}+\alpha_{22}\left(r_{1, t-1} r_{2, t-1}\right)+\beta_{22} h_{12, t-1}, \\
& h_{22, t}=\omega_{3}+\alpha_{33}\left(r_{2, t-1}^{2}\right)+\beta_{33} h_{22, t-1} .
\end{aligned}
$$

Under this model, the dynamic variances are modelled as a function of their own previous conditional and unconditional variances. Similarly the dynamic covariance is modelled as a function of previous period conditional and unconditional covariances. We believe that this is a particularly appealing approach in the effort to analyse the effects of the financial crisis. Lagged effects are directly incorporated into the model so we can clearly identify how persistent are the effects of the crisis on the correlations between assets. The parameters of the model are estimated using standard maximum likelihood (MLE) methods.

In our discussion we have assumed that the variables $r_{1}$ and $r_{2}$ are stationary and zero mean variables. As reported in Table 1, all return series used have very low first-order autocorrelations, thus they are likely stationary. Moreover, we formally test for stationarity using the standard augmented Dickey-Fuller (ADF) test. The results in Table 1 show that the $p$-values for the ADF test are very close to zero; thus we reject the null hypothesis of unit root for all return series. With this result, we model our original series following a standard $\operatorname{AR}(p)$ model and use the zero mean residuals for the MGARCH model. ${ }^{13}$

\section{Are CAT bonds zero-beta assets? Empirical evidence}

We first focus on analysing if CAT bonds are zero-beta investments by estimating their dynamic correlations with the stock, corporate bond and government bond markets.

${ }^{13}$ In fact, the $\operatorname{AR}(p)$ and the MGARCH models are jointly estimated by MLE. We use standard test to select the value of $p$, for our model. We also tested our results using $\operatorname{ARMA}(p, q)$ models. 


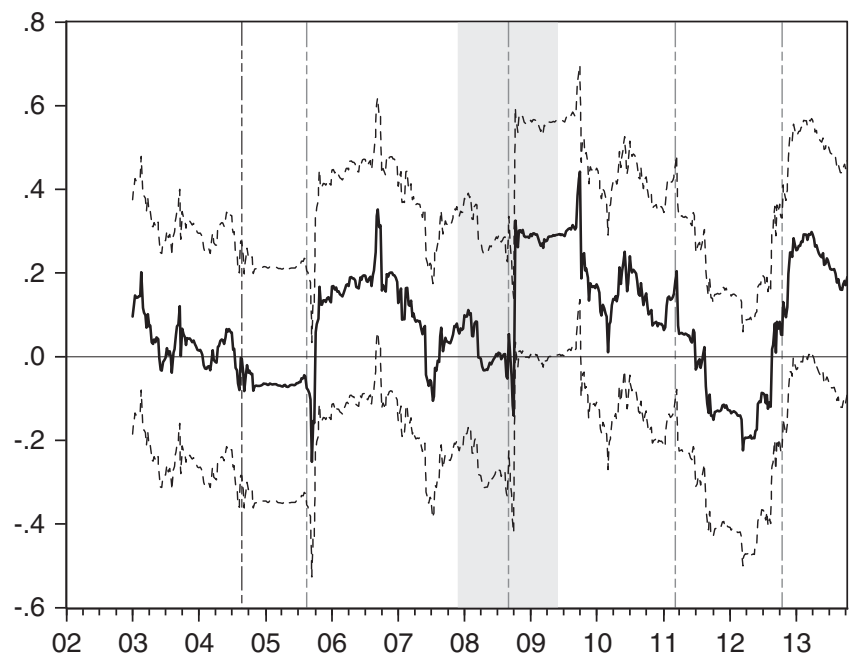

Figure 4. Rolling correlations of CAT bonds and market index returns.

The solid line in the figure is the rolling correlation coefficient between CAT bonds returns and the returns of the S\&P500 index as defined in Eq. (2). The rolling window is 52 weeks. The dotted lines represent the corresponding 95 per cent confidence interval for the correlations. The shaded area in the graph corresponds to the financial crisis period and the dotted lines represent the occurrence of five major insurance catastrophes during our sample period: 2 September 2004, Hurricane Ivan (US\$15.672 billion); 25 August 2005, Hurricane Katrina (US\$76.254 billion); 6 September 2008, Hurricane Ike (US\$21.585 billion); 11 March 2011, the Japanese earthquake and tsunami (US\$37.735 billion); 24 October 2012, Hurricane Sandy (US\$35 billion).

As previously explained, our proxies for these markets are the S\&P500 index, the FINRABloomberg Active Investment Grade U.S. Corporate Bond and the Barclays 5-7 year U.S. government bond indexes respectively.

We start by estimating the rolling correlation coefficient, as defined in Eq. (2), between CAT bonds returns and the stock market index returns. We define our rolling window to be the previous 52 weeks. ${ }^{14}$ The estimated rolling correlation coefficients and the corresponding 95 per cent confidence interval limits are reported in Figure 4. According to the National Bureau of Economic Research, the recession related to the subprime financial crisis started in December 2007 and ended in June 2009. This period is identified in Figure 4 (and all subsequent figures) as a shaded area. Barrieu and Loubergé ${ }^{15}$ argue that there is a potential relation between the occurrence of an important natural catastrophe and a market crash while, and as discussed earlier, Gürtler et al. ${ }^{5}$ suggest that natural catastrophes have an impact on CAT bond premiums. If indeed a major catastrophe increases premiums for CAT bonds and causes important drops in the stock markets, then the corresponding correlations should also increase. In order to analyse and understand the possible impact of such events, we include in Figure 4 (and subsequent figures) the five catastrophes with the largest

${ }^{14}$ As robustness check, we also use 26 and 78 weeks as rolling windows. Results, presented in Appendix, Figure A2, show that all rolling correlations fall in the 95 per cent confidence interval of the 52-week rolling correlation.

15 Barrieu and Loubergé (2009). 
insurance losses during our sample period: Hurricane Katrina (US\$76.254 billion), ${ }^{16}$ the Japanese earthquake and tsunami (US\$35.735 billion), Hurricane Sandy (US\$35 billion), Hurricane Ike (US\$21.585 billion) and Hurricane Ivan (US\$15.672 billion). The occurrence of each of the five events is depicted with a vertical dotted line in each graph. Hurricane Ike occurred during the financial crisis in September 2008, the same month of the Lehman Brothers collapse.

The results presented in Figure 4 confirm Cummins and Weiss ${ }^{4}$ preliminary evidence. There is not significant evidence of correlation between the returns of CAT bonds and the returns of our stock market index for the period prior to the financial crisis. The correlation coefficients become large and significant in September 2008, and remain statistically different from zero until the end of 2009. During this period the correlation coefficient ranges from 0.33 in the second week of October 2008, to 0.44 in the second week of October 2009. The average correlation coefficient during this crisis period is 0.29 , almost identical to the constant correlation coefficient of 0.305 estimated by Cummins and Weiss. ${ }^{4}$ The results also suggest that correlations increase after every major catastrophic event but the increases are not significant. Even Katrina, the event with the largest insurance losses in our sample, failed to drive correlation to significant territory.

A shortcoming of the rolling correlation coefficient is that it weights equally all observations for an arbitrary number of prior periods ( 52 weeks here) and gives zero weight to older observations. Thus, it is unclear under what assumptions it consistently estimates the conditional correlations. As an alternative, we estimate the time-varying correlations using MGARCH(1,1) with a diagonal-VEC specification as defined in Eq. (6). The estimation results reported in Table 3 show that our $\operatorname{MGARCH}(1,1)$ specification captures the dynamic behaviour of the series as most coefficients are significant. The significance of the $\beta_{22}$ coefficient suggests that the dynamic correlations of our three asset classes and the S\&P500 are dominated by a strong GARCH process.

Using these estimation results, we proceed to estimate the dynamic correlations for our series. In Figure 5, we present the time-varying correlation between the stock market and CAT bonds returns under the estimated MGARCH process. It is interesting to note that, similar to the rolling correlation case, the correlation is not immediately affected by the financial crisis. We find that the correlation is close to zero until the end of August 2008. Up to this time, this result is consistent with the hypothesis that CAT bonds are designed in a way that attempts to isolate investors from market risks. However, the correlation slowly starts to increase in September 2008, from 0.0036 in the middle of September 2008 to 0.138 at the end of December 2008, reaching the highest value for 2009 of 0.24 around the middle of May. This change in the behaviour of the correlation coincides with the timing of critical events that took place in September 2008, notably the Lehman Brothers collapse and the Fannie Mae and the Freddie Mac nationalisations. As discussed in the next section, these critical events exposed a number of weaknesses in the structure of CAT bonds which allowed investors' exposure to market-related risk.

From May 2009 until the end of 2010, correlation registers large variations, reaching values as high as 0.34 at the beginning of January 2010 and as low as 0.06 at the end of the same month. This level of correlations variability is consistent with the market instability

\footnotetext{
${ }^{16}$ U.S. billion dollars indexed to 2012. Data obtained from Swiss Re.
} 
Table 3 MGARCH estimation results

\begin{tabular}{lccc}
\hline & S\&P500 returns & Corporate bond returns & Government bond returns \\
\hline & & & \\
$\omega_{1}$ & $0.00^{* * *}$ & $0.00^{* * *}$ & $0.00^{* * * *}$ \\
$\omega_{2}$ & $(4.15)$ & $(4.26)$ & $(9.54)$ \\
& $0.00^{*}$ & $0.00^{* *}$ & 0.00 \\
$\alpha_{11}$ & $(1.68)$ & $(2.38)$ & $(1.55)$ \\
& $104.66^{* * *}$ & $113.77^{* * *}$ & $103.82^{* * *}$ \\
$\alpha_{22}$ & $(4.18)$ & $(4.47)$ & $(11.75)$ \\
& 0.61 & 1.61 & 1.79 \\
$\alpha_{33}$ & $(0.65)$ & $(0.41)$ & $(0.33)$ \\
& $24.14^{* * *}$ & $25.50^{* * *}$ & $5.84^{* * *}$ \\
$\beta_{11}$ & $(2.72)$ & $(2.98)$ & $(3.07)$ \\
& $30.14^{* * *}$ & $33.93^{* * *}$ & $39.16^{* * *}$ \\
$\beta_{12}$ & $(5.83)$ & $(6.93)$ & $(15.05)$ \\
& $97.31^{* * *}$ & $89.24 * * *$ & $85.69^{* * *}$ \\
$\beta_{33}$ & $(28.71)$ & $(6.32)$ & $(2.78)$ \\
& $83.42^{* * *}$ & $74.61 * * *$ & $93.32^{* * *}$ \\
Total system observations & $(17.25)$ & $(11.99)$ & $(43.72)$ \\
Log likelihood & 1220 & 1142 & 1220 \\
AIC & 4549.32 & 4975.13 & 5007.04 \\
BIC & -14.86 & -17.37 & -16.37 \\
\hline
\end{tabular}

We report estimation results of the MGARH model with a diagonal VEC representation as described in Eq. (6):

$$
\begin{aligned}
& h_{11, t}=\omega_{1}+\alpha_{11}\left(r_{1, t-1}^{2}\right)+\beta_{11} h_{11, t-1}, \\
& h_{12, t}=\omega_{2}+\alpha_{22}\left(r_{1, t-1} r_{2, t-1}\right)+\beta_{22} h_{12, t-1}, \\
& h_{22, t}=\omega_{3}+\alpha_{33}\left(r_{2, t-1}^{2}\right)+\beta_{33} h_{22, t-1},
\end{aligned}
$$

where $h_{i i, t}$ are the conditional variances and $h_{12, t}$ is the conditional covariance, between CAT bond returns and the S\&P500 returns (first column), corporate bond returns (column 2) and government bond returns (column 3). We report estimated coefficients, and in parenthesis the corresponding $z$-statistics. We also report the value of the log likelihood function, the Bayesian information criterion (BIC) and the Akaike information criterion (AIC). Given the lack of significance of $\omega_{2}$ in all models, we restrict this coefficient to be equal to zero in our reported results. The *, $* *, * * *$ represent significance at the 10,5 and 1 per cent significance levels, respectively.

observed during the years after the crisis. We interpret these results as evidence that the postcrisis correlation between the CAT bond and the stock markets is still adjusting while the markets are reaching a new equilibrium. These adjustment period effects cannot be observed by simply analysing the rolling coefficients, since the jumps and decreases after the crisis are averaged out under the rolling methodology. Finally we find evidence that the effects of the financial crisis disappear at the beginning of 2011, and remain low during 2011 and most of 2012 until the occurrence of Hurricane Sandy, in October 2012.

We also observe an increase in the dynamic correlations due to major catastrophes. Figure 5 clearly shows a jump in dynamic correlations after each of the five major catastrophic events in our sample. The effect of Hurricane Ivan (US\$15.7 billion in insured losses) is not too pronounced. The occurrence of Hurricane Ike (US\$21.6 billion in insured losses) in September 2008 coincides with the Lehman Brothers collapse and Fannie Mae and the Freddie Mac nationalisations. Therefore, the very high correlations observed since the 


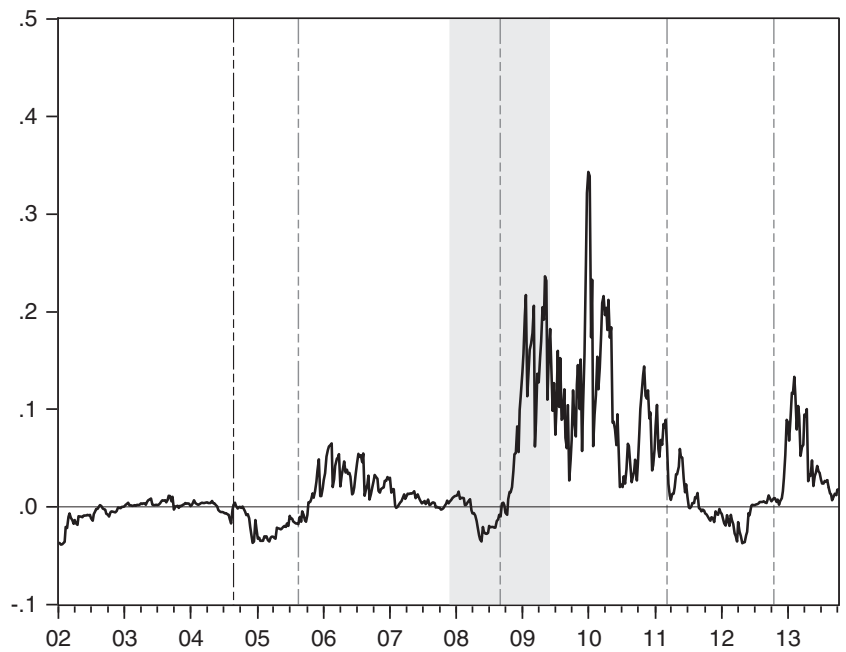

Figure 5. MGARCH correlations of CAT bonds and market index returns.

The solid line in the figure represents the MGARCH time-varying correlation between CAT bonds returns and the returns of the S\&P500 index. Correlations are based on an $\operatorname{MGARCH}(1,1)$ with a diagonal-VEC specification as defined in Eq. (6). The shaded area in the graph corresponds to the financial crisis period and the dotted lines represent the occurrence of five major insurance catastrophes during our sample period: 2 September 2004, Hurricane Ivan (US\$15.672 billion); 25 August 2005, Hurricane Katrina (US\$76.254 billion); 6 September 2008, Hurricane Ike (US\$21.585 billion); 11 March 2011, the Japanese earthquake and tsunami (US\$37.735 billion); 24 October 2012, Hurricane Sandy (US\$35 billion).

end of 2008 until the beginning of 2011 are, in all likelihood, the result of the combined effect of the critical events during the financial crisis and Hurricane Ike. We argue that, although it has certainly contributed to the increase, it is unlikely that Hurricane Ike alone could have triggered the big change in correlations observed during its aftermath. For example, a large event such as Katrina in 2005 (US\$75.25 billion in insured losses) and the Japanese earthquake and tsunami in March 2011 (US\$37.7 billion in insured losses) did not have as pronounced an effect in the magnitude and persistency of correlations. Hurricane Sandy in October 2012 (US\$35 billion in insured losses) had a more pronounced effect than either Katrina or the Japanese earthquake and tsunami, but a much smaller one than the combined impact of Hurricane Ike and the financial crisis. Given the impact of Sandy one may argue that the crisis may have induced a shift of "sentiments" among investors and has made them more sensitive to catastrophe events. Alternatively, we argue that events during the financial crisis such as the nationalisation of Fannie Mae and Freddie Mac and, more importantly, the collapse of Lehman Brothers, a central player in the CAT bond market, appear to have exposed a number of weaknesses in the structure of certain CAT bonds and, thus, seem to be the main drivers behind the dramatic increase in correlation and, more importantly, its persistence.

The graphical representation of the evolution of time-varying correlation in Figure 5 provides convincing evidence of any changes that have occurred. However, one may argue that by just looking at a graph it may be difficult to identify clearly the magnitude and persistence of such changes. In an effort to formally evaluate the dynamic behaviour of the 
Table 4 Markov switching model

\begin{tabular}{lccc}
\hline & S\&P500 returns & Corporate bond returns & Government bond returns \\
\hline Low correlation regime mean & $0.0022^{* *}$ & $0.0046^{* * * *}$ & -0.0000 \\
& $(2.61)$ & $(3.72)$ & $(-0.30)$ \\
High correlation regime mean & $0.0900^{* * *}$ & $0.1621^{* * *}$ & $0.1610^{* * *}$ \\
& $(17.76)$ & $(30.09)$ & $(19.34)$ \\
Over all mean & 0.0275 & 0.0133 & 0.0051 \\
Observations & 614 & 575 & 614 \\
\hline
\end{tabular}

We report estimation results of a two-regime Markov switching model. We report the estimated mean for the dynamic correlations between CAT bonds returns and: the S\&P500 returns (first column), corporate bond returns (column 2) and government bond returns (column 3) for a high correlation regime and a low correlation regime. The corresponding $z$-statistics are reported in parenthesis. The *, **,*** represent significance at the 10,5 and 1 per cent significance levels, respectively.

series, we apply Hamilton's ${ }^{6}$ two-state Markov regime-switching model. This methodology models the dynamic correlations as a combination of two different stochastic processes (regimes). The approach allows us to identify low and high correlation regimes as well as the value of the correlations during these regimes and to test for their statistical significance. More importantly, the model provides estimated regime probabilities that help us identify during what periods the correlations were more likely to be in a high correlation regime than in a low correlation regime. Table 4, column one, reports the estimated average correlation for the two possible regimes in the model. The average correlation for the low regime is very small, 0.0022, and not significant at the 1 per cent significance level. The average correlation for the high correlation regime is 0.09 , statistically significant and more than 40 times larger than the one for the low correlation regime. Using the estimated parameters, we calculate regime probabilities, that is, the probability that the correlation series is in a high or low regime. We report the estimated regime probabilities for the high regime in Figure 6 . The results clearly confirm our inferences from Figure 5. We observe four time intervals with large probabilities of high correlation regime: (i) December 2005 to August 2006, (ii) October 2008 to beginning of March 2011, (iii) April 2011 to June 2011, and (iv) December 2012 to July 2013. As we can see from Figure 6, all the high correlation regimes are linked to either a major catastrophe or the subprime financial crisis. However, it is also evident that the effect of the combined financial crisis and Ike events is much more pronounced. The high regime starting at the middle of the financial crisis in October 2008 lasts for almost 30 months. The other high regime periods all last less than 8 months. Consistent with our previous analysis, it is also apparent that this very persistent high correlation regime did not start at the beginning of the financial crisis in December 2007, but 10 months later in October 2008. Thus, it may be linked to both Hurricane Ike and the financial crisis events that occurred during September 2008. As noted earlier default events triggered by the crisis are likely the main drivers of this high and persistent correlation regime. Although it has certainly influenced the spike in correlations and exacerbated the impact, Hurricane Ike alone could not explain the magnitude and more importantly, the persistency of the change in correlations. It is our conjecture that Hurricane Ike served as a catalyst that brought further attention to the CAT bond market and helped expose some of its vulnerabilities during the crisis.

In summary, from the analysis of the dynamic correlation of CAT bonds returns with the stock market, we conclude that CAT bonds were not immune to the financial crisis. 


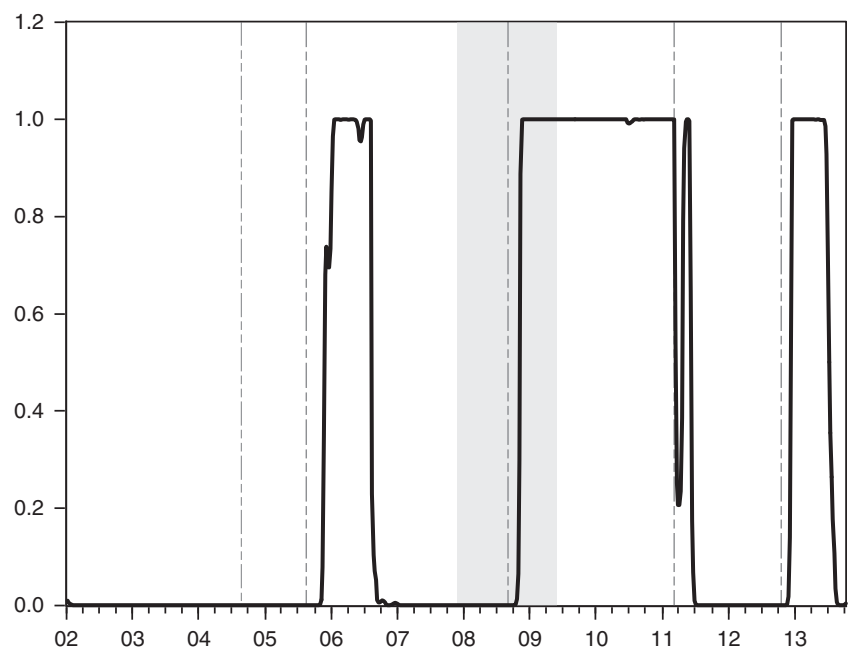

Figure 6. Regime probabilities correlations of CAT bonds and market index returns.

We report the Markov switching model smoothed switching probabilities that the correlations between CAT bonds and market index returns are in the high correlation regime. The shaded area in the graph corresponds to the financial crisis period and the dotted lines represent the occurrence of five major insurance catastrophes during our sample period: 2 September 2004, Hurricane Ivan (US\$15.672 billion); 25 August 2005, Hurricane Katrina (US\$76.254 billion); 6 September 2008, Hurricane Ike (US\$21.585 billion); 11 March 2011, the Japanese earthquake and tsunami (US\$37.735 billion); 24 October 2012, Hurricane Sandy (US\$35 billion).

In addition, the effects of the financial crisis on the CAT bond markets are highly persistent; however, we find evidence that correlations returned to pre-crisis levels by the beginning of 2011.

In the second step of our analysis of the market risk for CAT bonds, we analyse the relation of CAT bonds with the corporate bond market. Using the same approach, first we estimate rolling correlation coefficients between CAT bonds returns and returns of the corporate bonds index. The results, reported in Figure 7, show that correlations of CAT bonds with the bond markets are only significant for the period from October 2008 to approximately October 2010. The pattern is very similar to the one observed with the stock market.

Estimated dynamic correlations using the MGARCH model are presented in Figure 8. The results suggest that the correlation is close to zero before the crisis, with some jumps around major catastrophes, such as Hurricane Katrina in 2005. There is a big jump during the financial crisis, similar to the stock market's case, while it appears that the correlation comes back to pre-crisis levels at the end of 2009. Compared with the stock market's case, it seems that the correlation returned to pre-crisis values faster.

The results for the Markov switching model with respect to the correlation of CAT bonds with corporate bonds returns are reported in Table 4 (second column). There are two clearly identifiable regimes, a low correlation regime with average correlation of 0.0046 , and a high correlation regime with average correlation of 0.1621 . Both are statistically significant. Estimated probabilities for the high correlation regimes are reported in Figure 9. We can observe clearly two time intervals with large probabilities of high correlation. The first starts in October 2008 around the collapse of Lehman Brothers and after Hurricane Ike and ends in 


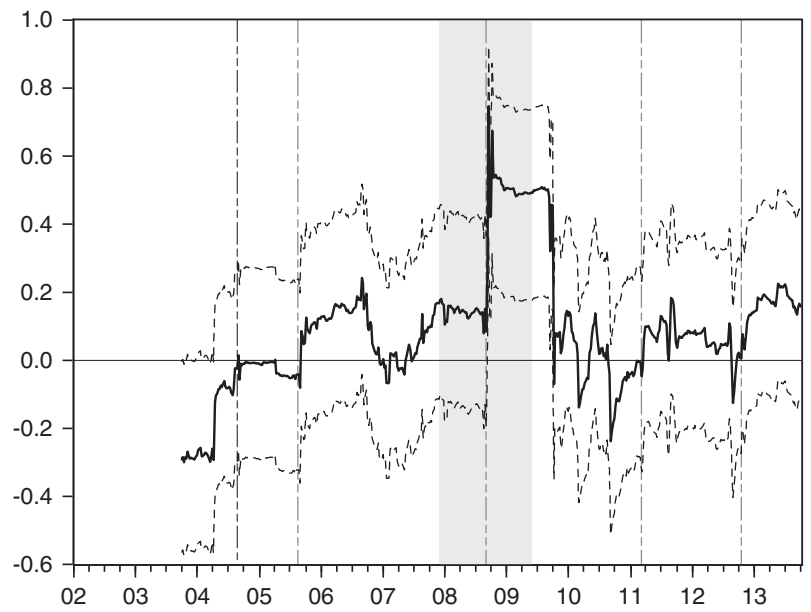

Figure 7. Rolling correlations of CAT bonds and corporate bond index returns.

The solid line in the figure is the rolling correlation coefficient as defined in Eq. (2) between BB CAT returns and the returns of the FINRA-Bloomberg Active Investment Grade U.S. Corporate Bonds Index. The rolling window is 52 weeks. The dotted lines represent the corresponding 95 per cent confidence interval for the correlations. The shaded area in the graph corresponds to the financial crisis period and the dotted lines represent the occurrence of five major insurance catastrophes during our sample period: 2 September 2004, Hurricane Ivan (US\$15.672 billion); 25 August 2005, Hurricane Katrina (US\$76.254 billion); 6 September 2008, Hurricane Ike (US\$21.585 billion); 11 March 2011, the Japanese earthquake and tsunami (US\$37.735 billion); 24 October 2012, Hurricane Sandy (US\$35 billion).

May 2009. Again, it is unlikely that this high correlation regime can be attributable to Hurricane Ike. As depicted in Figure 9, even the effects of Katrina on the correlations are negligible although Sandy, an event of almost double the losses compared with Ike, did seem to cause the second highest, albeit much shorter, high correlation regime from December 2012 to February 2013. It is interesting to note that the CAT bond to corporate bond high correlation regime caused by the financial crisis appears to persist for only six months, compared with a corresponding high correlation regime of approximately 2.5 years between the CAT bond index and the S\&P500.

We conclude that the effect of the financial crisis, combined with the effect from Hurricane Ike, on the relation of CAT bond and corporate bond markets was temporary but large. A new stable equilibrium relationship, similar to the pre-crisis one, was reached by May 2009.

In the final step of our analysis, we analyse the relation of CAT bonds with the government bond market. Rolling correlations results are presented in Figure 10. We find no significant correlation between the two markets, before, during or after the crisis. The only slightly significant correlation coincides with Katrina in August 2005.

Dynamic correlations, estimated using the MGARCH model, are presented in Figure 11. Overall, the results suggest an average correlation very close to zero, with relatively small variability. The only large spike in correlations appears at the end of 2004, which coincides with the big storm season of fall 2004 that started with Hurricane Ivan. We do not find a significant change on the relation of CAT bond market with the government bond market during the financial crisis. 


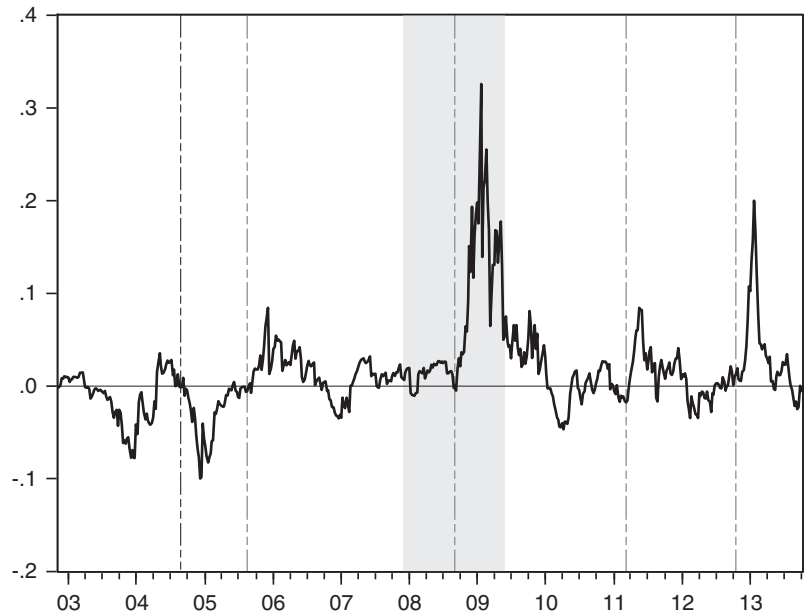

Figure 8. MGARCH correlations of CAT bond and corporate bond index returns.

The solid line in the figure represents the MGARCH time-varying correlation between BB CAT bond returns and the returns of the FINRA-Bloomberg Active Investment Grade U.S. Corporate Bond index. Correlations are based on an MGARCH(1,1) with a diagonal-VEC specification as defined in Eq. (6). The shaded area in the graph corresponds to the financial crisis period and the dotted lines represent the occurrence of five major insurance catastrophes during our sample period: 2 September 2004, Hurricane Ivan (US\$15.672 billion); 25 August 2005, Hurricane Katrina (US\$76.254 billion); 6 September 2008, Hurricane Ike (US\$21.585 billion); 11 March 2011, the Japanese earthquake and tsunami (US\$37.735 billion); 24 October 2012, Hurricane Sandy (US\$35 billion).

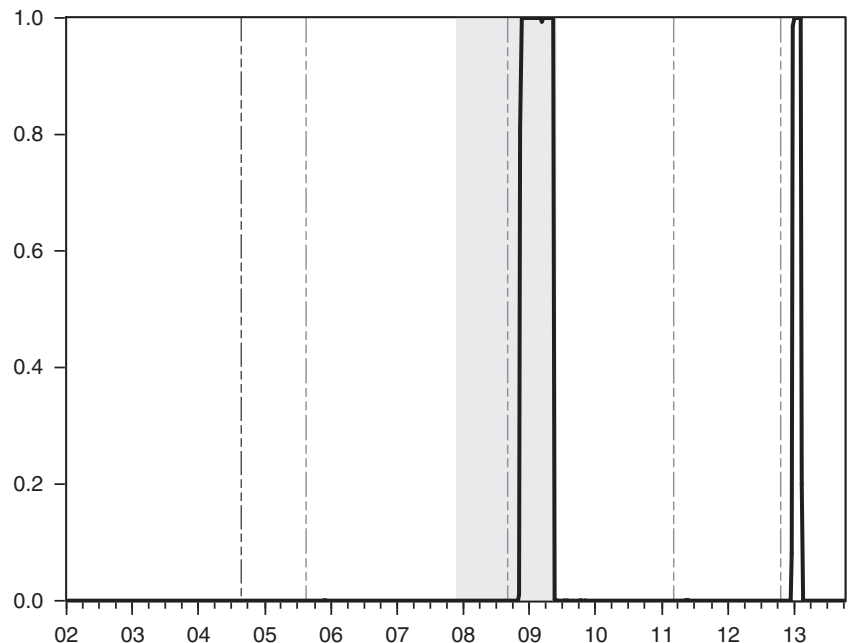

Figure 9. Regime probabilities correlations of CAT bond and corporate bond index.

We report the Markov switching model smoothed switching probabilities that the correlations between CAT bond and corporate bond index returns are in the high correlation regime. The shaded area in the graph corresponds to the financial crisis period and the dotted lines represent the occurrence of five major insurance catastrophes during our sample period: 2 September 2004, Hurricane Ivan (US\$15.672 billion); 25 August 2005, Hurricane Katrina (US\$76.254 billion); 6 September 2008, Hurricane Ike (US\$21.585 billion); 11 March 2011, the Japanese earthquake and tsunami (US\$37.735 billion); 24 October 2012, Hurricane Sandy (US\$35 billion). 


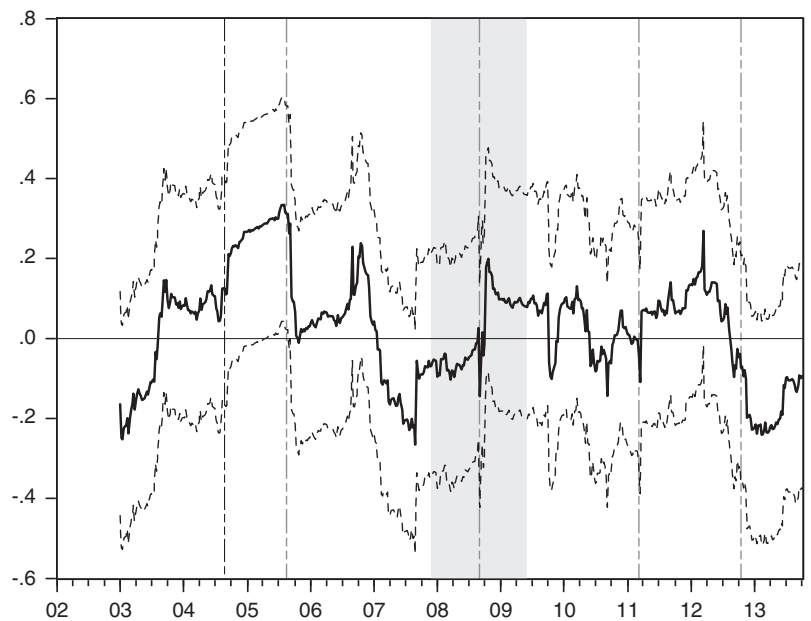

Figure 10. Rolling correlations of CAT bond and government bond index returns.

The solid line in the figure is the rolling correlation coefficient as defined in Eq. (2) between BB CAT bond returns and the returns of the Barclays 5-7-year government bond index. The rolling window is 52 weeks. The dotted lines represent the corresponding 95 per cent confidence interval for the correlations. The shaded area in the graph corresponds to the financial crisis period and the dotted lines represent the occurrence of five major insurance catastrophes during our sample period: 2 September 2004, Hurricane Ivan (US\$15.672 billion); 25 August 2005, Hurricane Katrina (US\$76.254 billion); 6 September 2008, Hurricane Ike (US\$21.585 billion); 11 March 2011, the Japanese earthquake and tsunami (US\$37.735 billion); 24 October 2012, Hurricane Sandy (US\$35 billion).

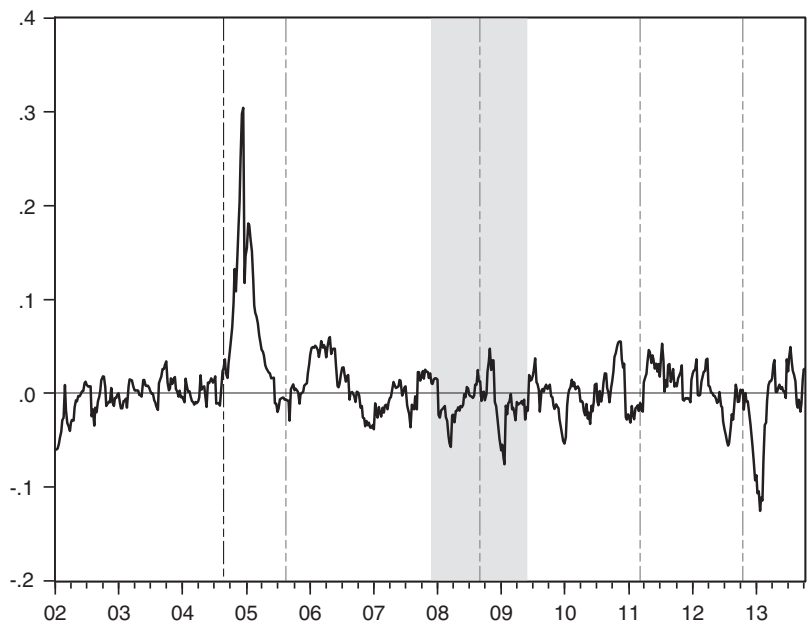

Figure 11. MGARCH correlations of CAT bond and government bond index returns.

The solid line in the figure represents the MGARCH time-varying correlation between BB CAT bond returns and the returns of the Barclays 5-7-year government bond index. Correlations are based on an MGARCH(1,1) with a diagonal-VEC specification as defined in Eq. (6). The shaded area in the graph corresponds to the financial crisis period and the dotted lines represent the occurrence of five major insurance catastrophes during our sample period: 2 September 2004, Hurricane Ivan (US\$15.672 billion); 25 August 2005, Hurricane Katrina (US\$76.254 billion); 6 September 2008, Hurricane Ike (US\$21.585 billion); 11 March 2011, the Japanese earthquake and tsunami (US\$37.735 billion); 24 October 2012, Hurricane Sandy (US\$35 billion). 


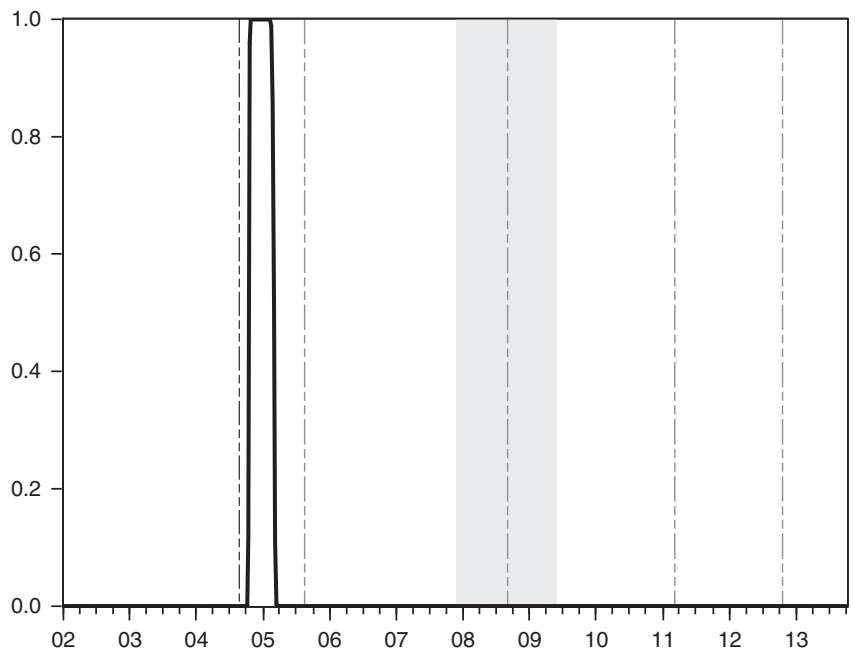

Figure 12. Regime probabilities correlations of CAT bond and government bond index.

We report the Markov switching model smoothed switching probabilities that the correlations between CAT bond and government bond index returns are in the high correlation regime. The shaded area in the graph corresponds to the financial crisis period and the dotted lines represent the occurrence of five major insurance catastrophes during our sample period: 2 September 2004, Hurricane Ivan (US\$15.672 billion); 25 August 2005, Hurricane Katrina (US\$76.254 billion); 6 September 2008, Hurricane Ike (US\$21.585 billion); 11 March 2011, the Japanese earthquake and tsunami (US\$37.735 billion); 24 October 2012, Hurricane Sandy (US\$35 billion).

Finally we apply the Markov switching approach to the correlations of CAT bonds and government bonds. Estimation results reported in Table 4 (column 3) while high regime probabilities are depicted in Figure 12. It appears there is no regime change during the financial crisis, and the only jump in correlations happened towards the end of 2004 in the aftermath of Hurricane Ivan.

In summary, our results suggest that, in fact, CAT bonds are not zero-beta assets and they were affected by the financial crisis. Furthermore, we find that the effect on the correlation of CAT bond returns with stock market returns was much more persistent than the effect on the correlation between the CAT bond and the corporate bond market. The effects of the financial crisis on both correlations, however, were more pronounced and persistent than the usual effects resulting from the natural disasters considered. It appears that the CAT bond correlation with the U.S. Treasury Bond market was unaffected by the financial crisis. In the next section we analyse the possible effects during the financial crisis that may have triggered the dramatic and persistent change in correlations documented in our empirical results.

\section{Subprime financial crisis and the effects in the CAT bond market}

As our analysis in the previous section indicated while there are often spikes in correlations between the CAT bond and the rest of the financial markets in the aftermath of natural disasters, the effects of the subprime financial crisis were more pronounced and persistent. The correlation coefficients became large and significant towards the end of 2008, and 
remained statistically different from zero for a considerable period. Thus, we can infer that CAT bonds were exposed to significant systematic risk during the financial crisis. This result is surprising to a certain extent since CAT bond offerings were designed in a way that attempted to isolate investors from market risks and expose them only to insurance risks. In support of such belief the spike in correlations did not coincide with the start of the financial crisis something. However, events surrounding the collapse of Lehman Brothers exposed a number of weaknesses in the structure of CAT bonds. In this section we investigate the role these events played on the behaviour of the CAT bond markets, factors that affected the increase in systematic risk and analyse the steps markets have taken to potentially mitigate the effects of these factors in the wake of future financial crises. The discussion in this section follows $\operatorname{Krutov}^{17}$ and Towers Watson. ${ }^{18}$ For a more detailed discussion of the issues that arose during the crisis and solutions that were developed, please refer to these publications.

The presence of the SPV and the TRS counterparty in the structure of the CAT bond were assumed to provide investor protection against fluctuating interest rates and changes in the collateral value. The high quality of the assets in the collateral account and the highly rated TRS counterparty that converted the fixed return on these assets to LIBOR-based returns for investors were thought to minimise exposure to market-related risks and provide investors with exposure only to the catastrophic risk underlined in the contract. However, the credit and liquidity crisis exposed a number of problems with assets in the collateral account, while it severely impacted the creditworthiness of some TRS counterparties.

There was often a duration mismatch between the assets in the collateral account and the CAT bond. Although CAT bonds often had maturities of three years or less, securities in the collateral account often had significantly longer maturities. Furthermore, assets in the collateral account often included structured products such as asset-backed securities (ABS) and mortgage-backed securities (MBS) which, while highly rated, were severely impacted in the course of the financial crisis. Both sponsors and investors often paid very little attention to the composition of the collateral assets. Furthermore, there were almost no requirements for the monitoring and reporting of the assets on a regular basis. To a certain extent this could be the result of the presence of a TRS counterparty which was supposed to absorb the impact of fluctuations in the value of the assets in the collateral account and guarantee LIBOR-based returns to investors. In addition, there was usually no requirement for the TRS counterparty to maintain the value of the collateral account above a certain threshold level. At the onset of the financial crisis a number of financial institutions that served as TRS counterparties were severely affected and weaknesses in the CAT bond structure emerged. In particular, the collapse of Lehman Brothers, which served as the TRS counterparty to four CAT bonds at the time, caused shock waves in the CAT bond market. Lehman Brothers was no longer able to meet its obligations with respect to these four bonds which were quickly downgraded by rating agencies. Although there was initial hope that a replacement counterparty could be found, these hopes quickly vanished as the value of the assets in the collateral account reduced as well. Distressed CAT bonds were put up for sale quickly, leading to depressed secondary prices in a market that was drained of liquidity. As a result, CAT bond investors

\footnotetext{
${ }^{17}$ Krutov (2010).

18 Towers Watson (2010).
} 
suffered losses not from natural catastrophic events, but from market risks that they thought they had been isolated from.

As a response to the problems that surfaced during the financial crisis, several solutions emerged that tried to address the credit and collateral issues associated with CAT bonds. As the issuance of CAT bonds resumed at the beginning of 2009, after a freeze in the last quarter of 2008, new and improved collateral solutions were utilised in the structure of these bonds. All these solutions attempted to enhance the credit quality of the collateral assets and the credit worthiness of the TRS counterparty. Additional limits were imposed to the type of assets permitted in the collateral account. Illiquid and hard-to-price structured assets such as AAA- or AA-rated ABS and CDOs were excluded from potential investment alternatives. Permissible assets were generally limited to cash, government-guaranteed bank debt, U.S. Treasury money market funds and customised putable notes by sovereign or quasigovernmental entities.

Particular emphasis was also placed in the monitoring and reporting of the collateral account with provisions such as mark-to-market (often daily) and added trustee responsibility for monitoring the collateral account on a regular basis to ensure the investment criteria were satisfied. In some cases triparty repo arrangements were established with a third party overseeing the daily valuation and movement of the collateral account. In some cases the presence of a TRS counterparty was completely eliminated and the trust account funds were invested in notes of appropriate maturity issued by sovereign or quasi-governmental organisations with government backing. A put option that allowed the sale of the notes back to the issuer on certain quarterly dates introduced an element of flexibility and allowed for the quick liquidation of assets in the case of the loss-triggering event described in the CAT bond contract.

Braun et al. ${ }^{19}$ show that an important driver of CAT bond demand is the regulatory regime applicable to this asset class. Thus, all these improvements in the CAT bond markets may explain in part our empirical results that provide evidence that correlations between CAT bonds and the market slowly returned to pre-crisis levels. Market participants may have perceived positively the latest changes in the structure of CAT bonds.

\section{CAT bonds asset class as a source of diversification}

Given the significant influence of the subprime financial crisis on the CAT bond market and the spike in correlations with other asset classes, the question still remains whether CAT bonds still constitute a good source of diversification. In this section we analyse this question and present some interesting results.

Our analysis is based on the construction of hedge ratios between our market proxy and three different investment opportunities: CAT bonds, corporate bonds and government bonds. Since the hedge ratios are estimated by the ratio of the covariance with the market and the variance of the market, they can be interpreted as time-varying betas. Once again our proxy for the market is the S\&P500 index return. We estimate the variances and covariances of each one of the test assets with the market using an MGARCH model and the estimated

${ }^{19}$ Braun et al. (2013). 


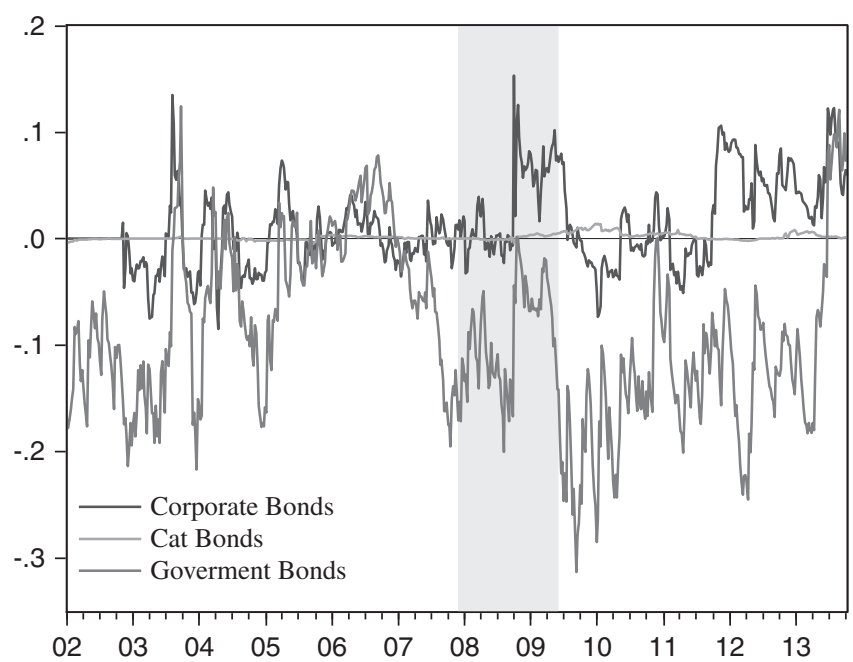

Figure 13. Hedge ratios with respect to the market factor.

The figure shows estimated dynamic hedge ratios with respect to the returns of the S\&P500 index (market factor) for the returns of our corporate bond index, our CAT bond index and our government bond index. Hedge ratios are estimated by the ratio of the covariance of each variable with the market factor and the variance of the market. Shaded area corresponds to the financial crisis periods.

hedge ratios are presented in Figure 13. Betas for CAT bonds are very close to zero until the collapse of Lehman Brothers. They start to increase around September 2008, reaching a maximum value of 0.014 in January 2010 and coming back to close to zero at the end of our sample period. However, the economic significance of these betas is questionable even at the maximum value.

We cannot deny the economical importance of the effect of the financial crisis on the corporate bond market. During the end of 2008 until the end of 2009 the hedge ratio became positive with a maximum value of 0.13 observed in September 2008. Results are not so clear for the government bond market. We can still observe the effect of the financial crisis with a big jump on hedge ratio from -0.17 on September 2008 to zero on October 2008 . However the evolution of the government bond beta seems to be much more complicated and unstable.

Overall, the relative change of CAT bonds hedge ratios during the financial crisis is extremely small compared with the one of other financial assets. Thus, we conclude that CAT bonds constitute an asset class that provides superior diversification opportunities to prudent investors.

Finally, as an additional test, we compare the hedge ratios between CAT bond and corporate bond returns. This analysis is interesting in the sense that an investor may introduce CAT bonds in a diversified portfolio consisting of corporate bonds in order to hedge the negative impact of the financial crisis. ${ }^{20}$ Estimated hedge ratios for CAT bonds

\footnotetext{
${ }^{20}$ We thank an anonymous referee for suggesting this analysis and interpretation.
} 


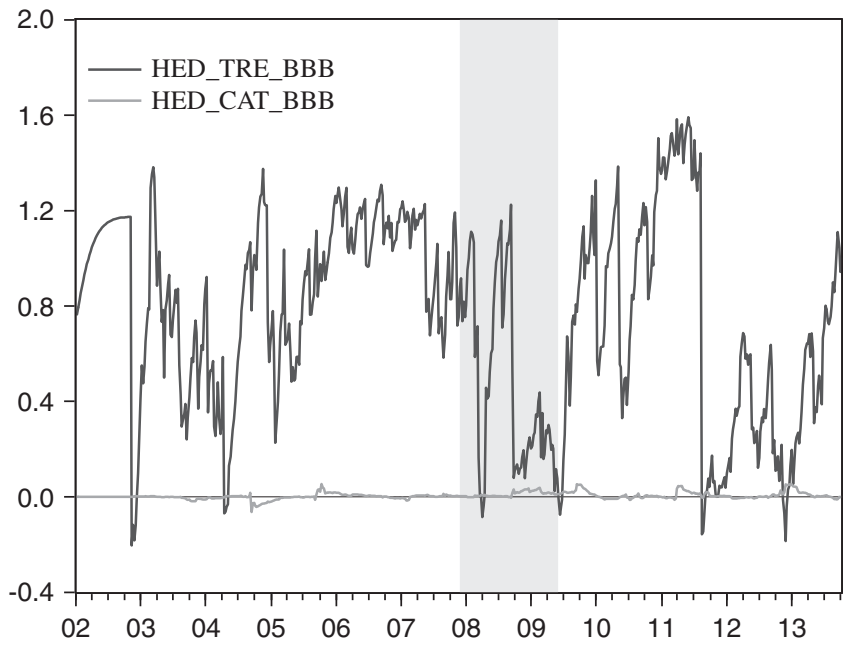

Figure 14. Hedge ratios with respect to the bond factor.

The figure show estimated dynamic hedge ratios with respect of the returns to the corporate bond index (bond factor) for the returns of our CAT bond index and our government bond index. Hedge ratios are estimated by the ratio of the covariance of each variable with the market factor and the variance of the bond market. Shaded area corresponds to the financial crisis periods.

with respect to corporate bonds are presented in Figure 14. As a comparison, hedge ratios of government bonds and corporate bonds are also presented. The expectation is that if CAT bonds are a good hedging instrument relative to government bonds, then its hedge ratios should not be significantly affected by the crisis. The behaviour of hedge ratios depicted in Figure 14 confirms our results; hedge ratios for CAT bonds are very close to zero during all sample periods, and they are not significantly affected by the crisis. Government bond hedge ratios drop significantly after September 2008 and remain low until the end of the crisis. We conclude that the CAT bond market is a useful source of diversification in the context of a Corporate bond portfolio.

\section{Conclusion}

We use a multivariate GARCH approach to study the behaviour of the relationship between CAT bonds and each of the stock, corporate and government bond markets for the period from January 2002 to October 2013. Our analysis provides evidence that, contrary to prior beliefs that considered them immune to changes in systematic risk, CAT bonds were affected considerably during the subprime financial crisis, exhibiting a behaviour not consistent with a zero-beta instrument. This was mainly due to weaknesses associated with the composition and the structure of the trust account. Assets used as collateral in the trust account proved to be of lesser quality than what it was thought originally. Furthermore, counterparties in swap agreements, put in place in an effort to immunise collateral asset returns from market fluctuations, were exposed to considerable credit risk or even defaulted during the crisis. 
However, an analysis of estimated hedge ratios of CAT bonds and other assets provides evidence that, despite the impact of the financial crisis on them, CAT bonds are still a valuable source of diversification and an asset class that should not be ignored by investors. Furthermore, steps taken after the crisis to improve the structure of the CAT bonds and further isolate investors from market risks have probably improved the diversification benefits of this asset class even further. To what extent, however, would be the subject of further research in the context of future events that could put pressure on and increase systematic risk in the financial markets.

\section{References}

Barrieu, P. and Loubergé, H. (2009) 'Hybrid cat bonds', The Journal of Risk and Insurance 76(3): 547-578.

Braun, A. (2011) 'Pricing catastrophe swaps: A contingent claims approach', Insurance: Mathematics and Economics 49(3): 520-536.

Braun, A., Mueller, K. and Schmeiser, H. (2013) 'What drives insurers' demand for cat bond investments? Evidence from a Pan-European survey', The Geneva Papers on Risk and Insurance-Issues and Practice 38(3): 580-611.

Chang, C.W., Chang, J.S. and Lu, W. (2010) 'Pricing catastrophe options with stochastic claim arrival intensity in claim time', Journal of Banking \& Finance 34(1): 24-22.

Cummins, D. and Weiss, M.A. (2009) 'Convergence of insurance and financial markets: Hybrid and securitized risk-transfer solutions', The Journal of Risk and Insurance 76(3): 493-545.

Dieckmann, S. (2009) By force of nature: Explaining the yield spread on catastrophe bonds, working paper, Philadelphia: University of Pennsylvania.

Egami, M. and Young, V.R. (2008) 'Indifference prices of structured catastrophe (CAT) bonds', Insurance: Mathematics and Economics 42(2): 771-778.

Engle, R. and Kroner, K. (1995) 'Multivariate simultaneous generalized ARCH', Econometric Theory 11(1): 122-150.

Gürtler, M., Hibbeln, M. and Winkelvos, C. (2012) The impact of the financial crisis and natural catastrophes on CAT bonds, Technische Universität Braunschweig, Institute of Finance, Working Paper No. IF40V1.

Guy Carpenter (2012) Catastrophes, Cold Spots and Capital. Navigating for Success in a Transitioning Market, Renewal Report.

Hamilton, J. (1989) 'A new approach to the economic analysis of nonstationary time series and the business cycle', Econometrica 57(2): 357-384.

Härdle, W.K. and Cabrera, B.L. (2010) 'Calibrating CAT bonds for Mexican earthquakes', The Journal of Risk and Insurance 77(3): 625-650.

Kroner, K.F. and Sultan, J. (1993) 'Time-varying distributions and dynamic hedging with foreign currency futures', Journal of Financial and Quantitative Analysis 28(4): 535-551.

Krutov, A. (2010) Investing in Insurance Risk: Insurance-Linked Securities-A practitioner's Perspective, London: Risk Books.

Lane, M.N. and Mahul, O. (2008) Catastrophe risk pricing: an empirical analysis, Working Paper No. 4765, Washington, DC: The World Bank.

Lee, J.P. and Yu, M.T. (2007) 'Valuation of catastrophe reinsurance with catastrophe bonds', Insurance: Mathematics and Economics 41(2): 264-278.

Litzenberger, R.H., Beaglehole, D.R. and Reynolds, C.E. (1996) 'Assessing catastrophe reinsurance-linked securities as a new asset class', Journal of Portfolio Management 23(special issue): 76-86.

Muermann, A. (2008) 'Market price of insurance risk implied by catastrophe derivatives', North American Actuarial Journal 12(3): 221-227.

Towers Watson (2010) Catastrophe Bonds Evolve To Address Risk Issues, report.

Wu, Y.C. and Chung, S.L. (2010) 'Catastrophe risk management with counterparty risk using alternative instruments', Insurance: Mathematics and Economics 47(2): 234-245. 


\section{APPENDIX}

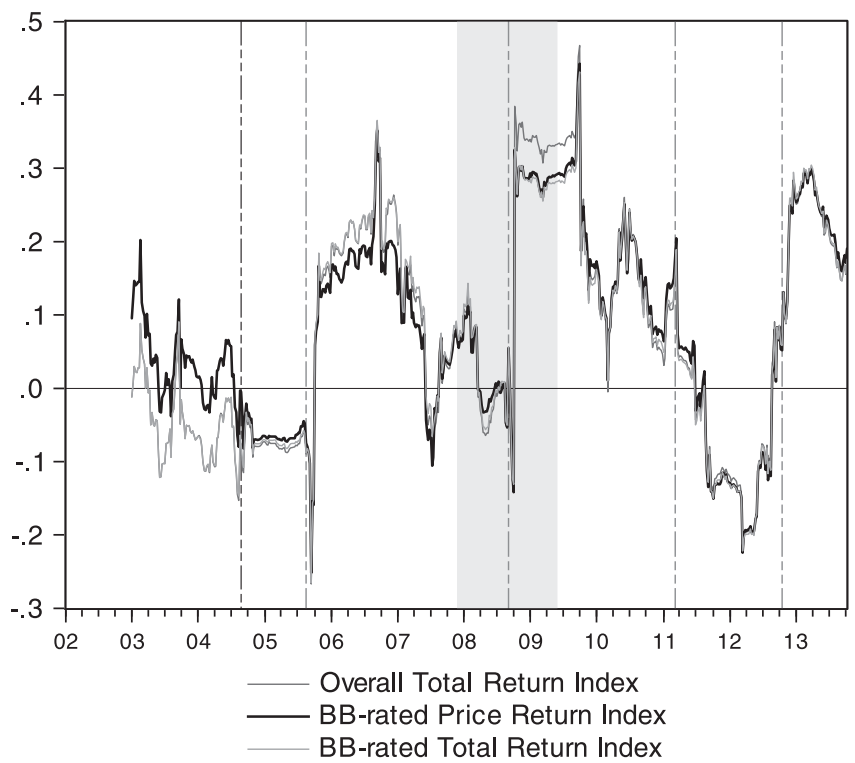

Figure A1. Robustness for different CAT bond indexes.

Notes: The figure shows the dynamic behaviour of the three different CAT bond index returns. We report the rolling correlations (52-week window) between the CAT bond returns and the S\&P500 index. Three different CAT bond indexes, compiled by Swiss Re, are used to calculate CAT bond returns: (i) BB CAT price bond index, BB CAT total return index and Overall total return index. The BB CAT price bond index is the one used in the paper. The shaded area in the graph corresponds to the financial crisis period and the dotted lines represent the occurrence of five major insurance catastrophes during our sample period: 2 September 2004, Hurricane Ivan (US\$15.672 billion); 25 August 2005, Hurricane Katrina (US\$76.254 billion); 6 September 2008, Hurricane Ike (US\$21.585 billion); 11 March 2011, the Japanese earthquake and tsunami (US\$37.735 billion); 24 October 2012, Hurricane Sandy (US\$35 billion). 


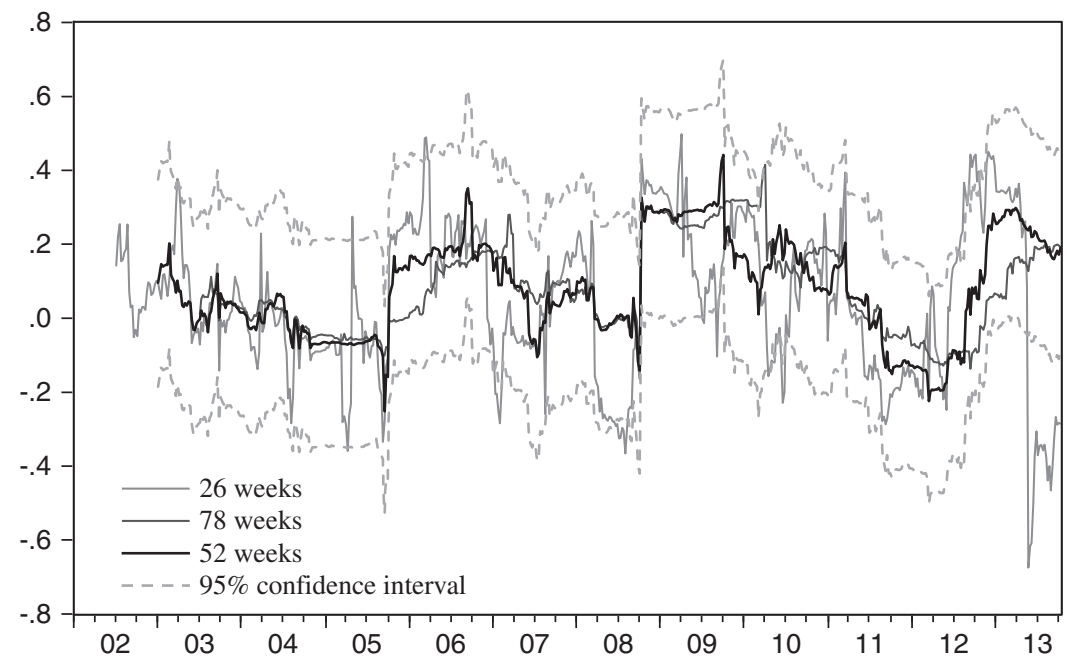

Figure A2. Robustness for different rolling windows.

Note: The solid line in the figure is the rolling correlation coefficient as defined in Eq. (2) between returns on the CAT bond index and the returns of the S\&P500 index with a 52-week rolling window. The dotted lines represent the corresponding 95 per cent confidence interval for these correlations. Also reported are rolling correlations using other rolling windows, 26 weeks and 78 weeks.

\section{About the Authors}

Peter Carayannopoulos is Associate Professor of Finance at Wilfrid Laurier University. $\mathrm{He}$ has an MBA and a PhD (Finance) from York University, Toronto. His research interests are in the areas of fixed income, embedded options, financial risk management and insurance.

M. Fabricio Perez is Assistant Professor of Finance at Wilfrid Laurier University. He received his $\mathrm{PhD}$ from Arizona State University. His research interests include financial econometrics with focus on asset pricing models and corporate finance. 